\title{
Dissecting Survival Pathways in Lung Cancer, Fibrosis and Emphysema: "The Four Horses of the Apocalypse"
}

\author{
Argyris Tzouvelekis ${ }^{\mathrm{a}}$ Vasilios Tzilas ${ }^{\mathrm{a}}$ Spyridon Papiris ${ }^{\mathrm{b}}$ Demosthenes Bouros ${ }^{\mathrm{a}}$ \\ ${ }^{a}$ First Academic Department of Pneumonology, Hospital for Diseases of the Chest, "Sotiria," Medical School, \\ National and Kapodistrian University of Athens, and ${ }^{\mathrm{b}}$ 2nd Pulmonary Medicine Department, Attikon University \\ Hospital, Medical School, National and Kapodistrian University of Athens, Athens, Greece
}

Pestilence, War, Famine and Death were the four Horses of the Apocalypse described in the Book of Revelation, the last book of The New Testament of the Bible, which was written by John, in the year $96 \mathrm{AD}$, on the Greek island of Patmos during the years of the Roman Emperor Domitian. Though being the element of constant dispute between theologians and historians, the Book of Revelation was initially believed to represent a symbolic prophecy of the subsequent history of the Empire.

Lung cancer, pulmonary fibrosis and chronic obstructive pulmonary disease (COPD-emphysema) represent the 3 leading causes of death from respiratory diseases in the world [1]. The past 10 years have seen the emergence of major advances in phenotyping clinical behaviour and treatment response of lung cancer based on the TNM pathological stage and molecular biomarkers, including epidermal growth factor receptor (EGF-R), ALK-4 and programmed-death ligand-1 (PD-L1) [2]. Similarly, the new GOLD grading system, based on spirometry, clinical symptoms and exacerbations, has refined disease prognosis and advanced therapeutic interventions [3]. Unfortunately, prognosis becomes more complicated and unpredictable in patients with idiopathic pulmonary fibro-

\section{KARGER}

(C) 2017 S. Karger AG, Basel

E-Mail karger@karger.com

www.karger.com/res sis (IPF), particularly in the presence of emphysema, reflecting the absence of timely and effective therapeutic options [4].

The co-existence of lung fibrosis and emphysema has been initially described as a separate syndrome, denominated combined pulmonary fibrosis and emphysema (CPFE), by Cottin et al. [5] in 2005; yet, it is highly debatable whether it represents a distinct syndrome or simply a coincidence of two lung diseases with similar aetiology. Patients with CPFE are characterized by different combinations of upper lobe emphysema and lower lobe fibrosis [6], relatively preserved lung volumes (counterbalance of emphysema and lung fibrosis in lung compliance), disproportionally reduced diffusion capacity for $\mathrm{CO}\left(\mathrm{DL}_{\mathrm{CO}}\right)$ (both processes cause significant damage to the alveolarcapillary membrane) and excessive desaturation during exercise. One of the major complications of CPFE is the increased risk of lung cancer development, mechanistically explained as "the triple-hit effect" of smoking, emphysema and fibrosis, all known risk factors for carcinogenesis. Lung cancer patients with CPFE represent an increasingly recognized specific entity with extremely poor prognosis and limited therapeutic options [7, 8]. Retrospective studies and recent meta-analyses have demon-

Prof. Demosthenes Bouros

Hospital for Diseases of the Chest, "Sotiria"

Medical School, National and Kapodistrian University of Athens

Messogion Ave. 152, GR-11527 Athens (Greece)

E-Mail dbouros@med.uoa.gr 
strated that CPFE is seen in almost $10 \%$ of lung cancer patients. The median survival is significantly lower (19 months) than that of lung cancer patients without underlying parenchymal disease (53 months) or with emphysema (22 months) or fibrosis (39 months) alone [9]. For us clinicians, one of the most troublesome dilemmas often encountered in routine clinical practice is the early identification of IPF and CPFE patients with lung cancer that will benefit from surgical interventions with minimal peri-operative and post-operative complications. With regard to the latter, clinical observations support the vulnerability of the lung and the high risk of acute exacerbation in patients with IPF and CPFE following lung resection [10].

In a recent issue of Respiration, Ueno et al. [11] investigated the potential usefulness of several preoperative biomarkers in predicting post-operative mortality in a cohort of patients with lung cancer and CPFE. The authors retrospectively reviewed 1,345 cases of patients that underwent lung surgery for primary lung cancer in a university hospital of Japan during a study period of 14 years. By applying stringent radiology criteria to quantify emphysema and fibrosis, they identified that besides the pathological stage of lung cancer, only composite physiologic index (CPI) reliably predicted disease mortality post-operatively. Impressively, cross-sectional application of a previously published CPI cut-off threshold in a different population of patients with IPF [12] exhibited excellent prognostic accuracy when used as a dichotomous variable. Individual pulmonary function components, extent of morphological changes in high-resolution computed tomography, as well as nutrition-associated and cancer biomarkers failed to provide correlations with disease mortality in multivariate survival analysis. The CPI represents a "severity" prognosticator that encompasses functional indices $\left(\mathrm{FEV}_{1}\right.$, forced vital capacity and $\mathrm{DL}_{\mathrm{CO}}$ ) and spares the need for radiographic scoring. It was seminally coined by Wells et al. [13] in 2003, and since then, it has been validated in large cohorts of patients with IPF and co-existing emphysema [12]. CPI presents with a unique advantage, as it includes $\mathrm{FEV}_{1}$ and $\mathrm{DL}_{\mathrm{CO}}$, and thus, it reflects disease severity without taking into account the effects of emphysema.

The study by Ueno et al. [11] exhibited several important attributes: (1) it was the first study in the field that tested the usefulness of 8 different prognostic indicators, including molecular, histological, physiological, radiological and cellular, in predicting mortality in a moderately sized cohort of patients with CPFE, (2) while it was anticipated that the pathological stage of lung cancer could be predictive of mortality; however, the effectiveness of a previously validated cut-off threshold of a clinical-physiological indicator to segregate patients with significantly different outcomes in a completely different cohort of CPFE patients is of pivotal importance. The latter highlights the fulfilment of the, so far, unmet need of a true biomarker in everyday clinical practice: non-interventional with ease of application and significant reproducibility; (3) finally, the authors addressed a major challenge for chest physicians: the validation of a clinical biomarker for the early identification of a group of patients presenting with a highly unpredictable clinical course and considerable mortality that could benefit from timely application of surgical interventions, both diagnostic and therapeutic.

Despite relative enthusiasm arising from the above observations, the study exhibited a number of caveats that should be interpreted cautiously. First, this was a unicentric retrospective analysis that exerted common methodological mistakes found in such types of approaches, including the inability to distinguish between phenomena and epiphenomena and prove cause-causality relationships as well as the generation of missing data by applying doubtful inclusion and exclusion criteria resulting in a reduction of the power of the study and potential selection bias. In relation with the latter, as stated by the authors, radiology assessment of the extent of emphysema and fibrosis was performed manually and, therefore, may have significantly affected the overall sample size. Second, the authors reported that a considerable percentage of individuals (13.5\%) included in the analysis had advanced IIIB-IV stage of lung cancer, which is practically inoperable. Selection bias towards patients with high post-operative and all-cause mortality may have skewed the CPI correlations with survival.

The identification of prognosticators that are clinician friendly, non-interventional and easy to be reproduced in routine clinical practice in cohorts of patients with lung cancer and CPFE may open new approaches that will guide diagnostic and therapeutic decisions with optimal effects and minimal complications. Currently, pre-operative evaluation for lung cancer resection only includes individual pulmonary function indices, exercise capacity and assessment of cardiovascular risk. A rational proposal would be to replace individual functional tests with the CPI or even produce a multidimensional prediction score by incorporating parameters of cardiovascular evaluation into the CPI. Larger studies are sorely needed to validate this premise that may exert a major impact on peri- and post-operative mortality. 


\section{References}

1 Burney P, Jarvis D, Perez-Padilla R: The global burden of chronic respiratory disease in adults. Int J Tuberc Lung Dis 2015;19:10-20.

2 Travis WD, Brambilla E, Nicholson AG, Yatabe Y, Austin JH, Beasley MB, Chirieac LR, Dacic S, Duhig E, Flieder DB, Geisinger K, Hirsch FR, Ishikawa Y, Kerr KM, Noguchi M, Pelosi G, Powell CA, Tsao MS, Wistuba I; WHO Panel: The 2015 World Health Organization classification of lung tumors: impact of genetic, clinical and radiologic advances since the 2004 classification. J Thorac Oncol 2015; 10:1243-1260.

3 Vogelmeier CF, Criner GJ, Martinez FJ, Anzueto A, Barnes PJ, Bourbeau J, Celli BR, Chen R, Decramer M, Fabbri LM, Frith P, Halpin DM, Lopez Varela MV, Nishimura M, Roche N, Rodriguez-Roisin R, Sin DD, Singh D, Stockley R, Vestbo J, Wedzicha JA, Agusti A: Global strategy for the diagnosis, management, and prevention of chronic obstructive lung disease 2017 report. GOLD Executive Summary. Am J Respir Crit Care Med 2017; 195:557-582.

4 Raghu G, Rochwerg B, Zhang Y, Garcia CA, Azuma A, Behr J, Brozek JL, Collard HR, Cunningham W, Homma S, Johkoh T, Martinez FJ, Myers J, Protzko SL, Richeldi L, Rind D, Selman M, Theodore A, Wells AU, Hoogsteden H, Schünemann HJ; American Tho- racic Society; European Respiratory Society; Japanese Respiratory Society; Latin American Thoracic Association: An official ATS/ERS/ JRS/ALAT clinical practice guideline: treatment of idiopathic pulmonary fibrosis. An update of the 2011 clinical practice guideline. Am J Respir Crit Care Med 2015;192:e3-e19. 5 Cottin V, Nunes H, Brillet PY, Delaval P, Devouassoux G, Tillie-Leblond I, Israel-Biet D, Court-Fortune I, Valeyre D, Cordier JF; Groupe d'Etude et de Recherche sur les Maladies Orphelines Pulmonaires (GERM O P): Combined pulmonary fibrosis and emphysema: a distinct underrecognised entity. Eur Respir J 2005;26:586-593.

6 Oikonomou A, Mintzopoulou P, Tzouvelekis A, Zezos P, Zacharis G, Koutsopoulos A, Bouros D, Prassopoulos P: Pulmonary fibrosis and emphysema: is the emphysema type associated with the pattern of fibrosis? World J Radiol 2015;7:294-305.

7 Karampitsakos T, Tzilas V, Tringidou R, Steiropoulos $\mathrm{P}$, Aidinis V, Papiris SA, Bouros D, Tzouvelekis A: Lung cancer in patients with idiopathic pulmonary fibrosis. Pulm Pharmacol Ther 2017, Epub ahead of print.

8 Bouros D, Hatzakis K, Labrakis H, Zeibecoglou K: Association of malignancy with diseases causing interstitial pulmonary changes. Chest 2002;121:1278-1289.
9 Koo HJ, Do KH, Lee JB, Alblushi S, Lee SM: Lung cancer in combined pulmonary fibrosis and emphysema: a systematic review and meta-analysis. PLoS One 2016; 11:e0161437.

10 Usui K, Tanai C, Tanaka Y, Noda H, Ishihara $\mathrm{T}$ : The prevalence of pulmonary fibrosis combined with emphysema in patients with lung cancer. Respirology 2011;16:326-331.

11 Ueno F, Kitaguchi Y, Shiina T, Asaka S, Miura K, Yasuo M, Wada Y, Yoshizawa A, Hanaoka M: The preoperative composite physiologic index may predict mortality in lung cancer patients with combined pulmonary fibrosis and emphysema. Respiration 2017; 94:198-206.

12 Mura M, Porretta MA, Bargagli E, Sergiacomi G, Zompatori M, Sverzellati N, Taglieri A, Mezzasalma F, Rottoli P, Saltini C, Rogliani $P$ : Predicting survival in newly diagnosed idiopathic pulmonary fibrosis: a 3-year prospective study. Eur Respir J 2012;40:101109.

13 Wells AU, Desai SR, Rubens MB, Goh NS, Cramer D, Nicholson AG, Colby TV, du Bois RM, Hansell DM: Idiopathic pulmonary fibrosis: a composite physiologic index derived from disease extent observed by computed tomography. Am J Respir Crit Care Med 2003; 167:962-969.
Survival Pathways in Lung Cancer, Fibrosis and Emphysema
Respiration 2017;94:239-241 DOI: $10.1159 / 000478910$ 